\title{
Factors affecting formation of adventitious branches in the seaweeds Fucus vesiculosus and F. radicans
}

\author{
Alexandra Kinnby * (1), Ricardo T. Pereyra, Jonathan N. Havenhand, Pierre De Wit, Per R. Jonsson, Henrik Pavia \\ and Kerstin Johannesson
}

\begin{abstract}
Background: In the brackish Baltic Sea, shedding of adventitious branches is central to asexual recruitment of new thalli in the brown algae Fucus vesiculosus and F. radicans. To test which factors influence the formation of adventitious branches in brackish and in more marine conditions, we sampled 29 Fucus sites in the Baltic Sea (salinity 3-11) and 18 sites from the Danish straits, Kattegat, Skagerrak, and the North Sea (salinity 15-35). Separately for each area, we used structural equation modelling to determine which of eight predictor factors (phosphate, nitrate, chlorophyll-a (as a proxy for turbidity), temperature, salinity, oxygen, grazing pressure, and thallus area) best explained observed numbers of adventitious branches.
\end{abstract}

Results: In more marine waters, high yearly average values of phosphate, salinity and turbidity had positive effects on the formation of adventitious branches. In brackish-waters, however, high numbers of adventitious branches were found in areas with low yearly average values of temperature, salinity and oxygen. Grazing intensity had no significant effect in either of the two study areas, contrasting findings from studies in other areas. In areas with both sexually and asexually reproducing Fucus individuals, clones had on average more adventitious branches than unique genotypes, although there was strong variation among clonal lineages.

Conclusion: This study is the first to investigate multiple potential drivers of formation of adventitious branches in natural populations of Fucus. Our results suggest that several different factors synergistically and antagonistically affect the growth of adventitious branches in a complex way, and that the same factor (salinity) can have opposing effects in different areas.

Keywords: Asexual reproduction, Baltic Sea, Macroalgae, North Sea, Salinity, Stress, Structural equation modelling

\section{Background}

Adventitious branches are new tissue grown from roots or stems in plants, or from the thallus in algae (Fig. 1). In terrestrial plants, adventitious branches are produced as a means of tissue repair and regeneration [1-3]. Growth of adventitious branches may be induced by grazing [4], but may also be induced by other stimuli, such as in trembling aspen (Populus tremuloides) where production of adventitious shoots on lateral roots is more affected by

\footnotetext{
${ }^{*}$ Correspondence: alexandra.kinnby@marine.gu.se Department of Marine Sciences, Tjärnö Marine Laboratory, University
} of Gothenburg, 45296 Strömstad, Sweden soil temperature (linked to fire) than by physical damage [5]. Additional stress factors reported to affect growth of adventitious branches in terrestrial plants include salt stress, hormone stress, light stress, removal of the apical bud, and chemical stress $[6,7]$.

In many marine macroalgae, adventitious branches are reported to develop as a way to heal wounds and regenerate tissue $[8,9]$. In the fucoid brown alga Fucus distichus, Van Alstyne [10], showed that the mean number of adventitious branches was positively correlated with the abundance of herbivorous marine snails (Littorina spp.), suggesting that tissue repair may be an important factor. Experimental changes in water temperature and light 

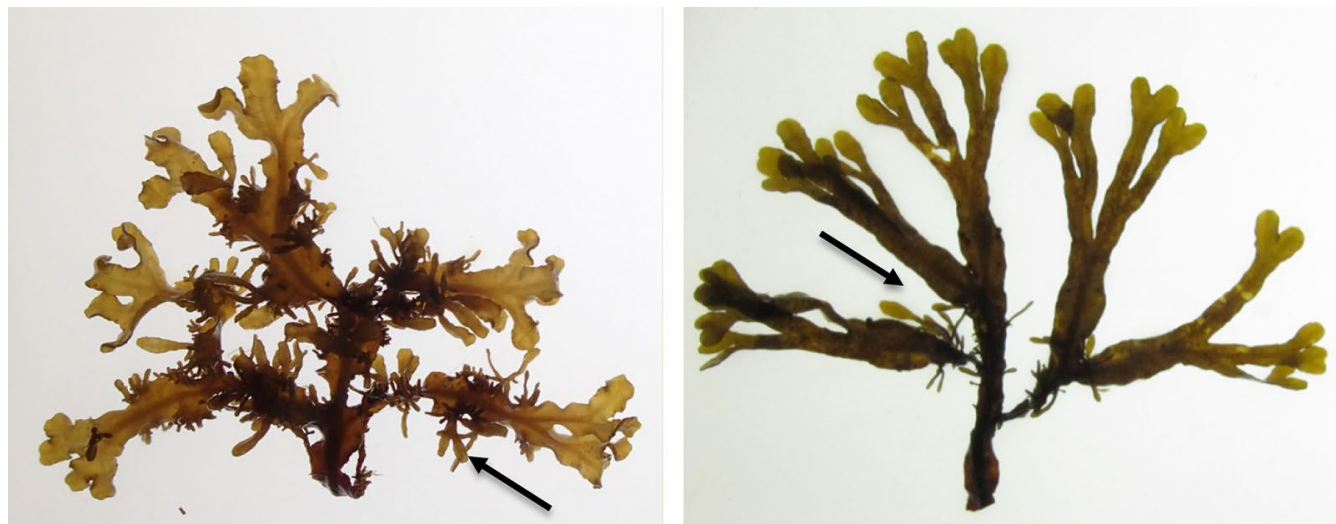

Fig. 1 Individuals of Fucus spp. with many and few adventitious branches

exposure can induce growth of adventitious branches in the fucoid Sargassum horneri [11]. However, adventitious branches have also been observed to be generated in F. distichus without any obvious physical stimulus [10], highlighting that the control mechanism is complex.

Fucus spp. can form adventitious branches from both the thallus and the holdfast $[10,12,13]$, and regeneration has been shown to be more common, and faster, from the midrib region of the thallus than from the thallus wings [12]. In many species of macroalgae, regeneration means apical growth of branched or un-branched filaments forming from the injury site. However, species of Fucus are atypical in this respect: epidermal cells divide perpendicularly to the surface and grow outwards, such that they develop into distinct 'embryos', as described by McCook and Chapman [14], instead of forming lateral branches [14]. These 'embryos' are morphologically indistinguishable from sexually produced embryos (sporelings) at early stages of development [12]. Although the adventitious branches resemble embryos, asexual reproduction of benthic thalli has not been observed in any Fucus species with one notable exception: in the Baltic Sea, detached adventitious branches produced by $F$. vesiculosus and $F$. radicans may reattach to the substratum by developing rhizoids, comparable to root hairs in vascular plants, and grow into new, seemingly functional male and female thalli, resulting in asexual recruitment of new individuals [15]. The reattachment of loose adventitious branches in Baltic Sea Fucus spp. has resulted in clones spread over extensive geographic areas $(550 \mathrm{~km})[16,17]$.

It remains unclear what factors determine the incidence of asexual reproduction in Fucus species in the Baltic Sea. Experimentally decreasing salinity lead to the cessation of receptacle formation in three Finnish populations while vegetative growth largely remained intact [18]. In addition, polyspermy has a negative impact on sexual reproduction through reduced fertilization success below a salinity of $6-8$, in the northern Baltic Sea [19, 20]. In any case, the formation of adventitious branches appears to be central to the evolution of asexual recruitment of the Baltic Sea Fucus.

We undertook an extensive mapping of the occurrence of adventitious branches in natural populations of $F$. vesiculosus and $F$. radicans inside and outside the Baltic Sea and used structural equation modeling to distinguish the effects of eight environmental factors, in order to investigate which factors promote the formation of adventitious branches in areas of different salinities. Based on prior knowledge that osmotic stress may induce formation of adventitious branches in vascular plants [6, 7], we hypothesized that salinity both inside and outside the Baltic Sea would have a strong effect on the prevalence of adventitious branches in fucoid seaweeds. Following an earlier report that adventitious branches correlate with grazer density [10], we also hypothesized that in areas with high grazing pressure, i.e. the more marine environment outside the Baltic Sea, tissue damage, measured as grazing marks, would promote formation of adventitious branches. In addition, we also included several other factors that may affect the formation of adventitious branches: temperature, oxygen, nitrate, phosphate, chlorophyll- $a$, and thallus area.

\section{Methods \\ Study areas}

The focus of this study was to distinguish which factors promote the formation of adventitious branches in Fucus spp. in sites located in two rather different environments: the Baltic Sea, and the transition zone (Danish straits, Kattegat, and Skagerack) and the eastern North Sea [21]. The two regions were separated with a line from Falsterbo in Sweden to Travemünde in Germany, following 
Johannesson and André [22] who found that for many taxa the area around this line separates two phylogeographic regions: the Baltic Sea and the eastern North Sea including the transition zone. Later studies have strongly corroborated this finding $[23,24]$.

In the Baltic Sea, the salinity (2-11) and surface water temperature decreases toward the north. Nutrient supply also declines from south to north, although the eastern Baltic Sea, including the Gulf of Finland, is nutrient-rich and eutrophic. The far north part, the Bay of Bothnia, is phosphorous-limited whereas the Baltic Sea proper is nitrogen-limited. The concentration of chlorophyll- $a$ in the water column follows that of nutrients: high in the Gulf of Finland, the Gulf of Riga and in the Baltic Proper while lower in the Gulf of Bothnia as well as towards the Danish Straits [21]. The main Fucus herbivore in the Baltic Sea is the isopod Idotea baltica [25].

In the transition zone and the eastern North Sea the surface salinity increases and temperature decreases and stabilizes from south to north, from a salinity of 15 and variable temperature in the Danish Straits to a salinity of 35 and more stable temperatures in the eastern North Sea $[21,26]$. A greater influence of deep, pelagic water from the Norwegian Trench lends a stabilizing influence in the north. Total dissolved nitrogen increases northwards in this area, while total dissolved phosphate and chlorophyll- $a$ decreases, with the overall levels of dissolved phosphate being somewhat higher than in the Baltic region in general [26]. The Fucus grazing community in the transition zone and the eastern North Sea is dominated by littorinid snails and isopods, and is more diverse than in the Baltic Sea $[25,27,28]$.

\section{Fucus vesiculosus and Fucus radicans}

Fucus radicans is a very young species, endemic to the Baltic Sea, and formed by a recent split from the Baltic lineage of $F$. vesiculosus $[29,30]$. Both species are dioecious (separate female and male individuals) and in the Baltic Sea, they reproduce both sexually and asexually through the formation of adventitious branches $[15,16]$ (Fig. 1). Due to their recent divergence, the morphologi$\mathrm{cal}$ and/or genetic discrimination into separate species is still challenging in some areas of the Baltic Sea (see [17, $30]$ ), including some localities from this study. We compared the number of adventitious branches between the two species in one sympatric site where they can be discriminated and found no significant difference (t-test, $\left.t_{43}=0.36 ; \mathrm{p}=0.72\right)$. Hence, for this study's purpose, we treated both taxonomic entities as Fucus spp.

\section{Sampling and image analysis}

Between 30 and 166 individuals of Fucus spp. were collected from each of 47 sites during September 2014
(Fig. 2). All individuals were photographed at the time of collection; small individuals were photographed in their entirety; larger individuals were subsampled by photographing one or a few large branches. The photographs were used to quantify the number of adventitious branches, and the surface area covered by the photo was estimated by image analysis in ImageJ [31].

Adventitious roots in terrestrial plants have been shown to form as a response to both mechanical and environmental stress [32, 33], including oxygen deprivation [34], and nutrient deficiency [33]. Studies looking at inducement of adventitious branches in algae are rare, but growth of adventitious branches in Sargassum horneri, (order fucales) is affected by temperature and light wavelength [11]. Thus, we conclude that a number of different abiotic variables may potentially affect growth of adventitious branches in Fucus spp., and we decided to explore five abiotic variables and three biotic variables (grazing pressure, thallus area, and chlorophylla) in our analysis. Data for salinity, temperature, nitrate, phosphate, oxygen, and chlorophyll- $a$ (affecting light penetration and hereafter referred to as turbidity) for each site were taken from monitoring data from the ICES database (International Council for the Exploration of the Seas: data were mean values for the years 2005-2015). Monitoring sites were located $2.0-77.0 \mathrm{~km}$ (average $16.7 \mathrm{~km}$ ) from the Fucus spp. sampling sites and sampled monthly to bimonthly. The majority of all Fucus spp. individuals included in our study showed no sign of grazing at all. Those that were grazed had clear grazing marks on the thallus but no major damage to the tissue, and so we assessed grazing pressure as presence or absence.

\section{DNA extraction and microsatellite genotyping}

DNA was extracted from lyophilized fresh algal tissue using a CTAB modified protocol for genomic DNA [35]. Following this, samples were genotyped at five microsatellite loci shown to be diagnostic in previous studies of fucoid species $[17,36]$. PCR products were pool-plexed and sized on a Beckman-Coulter CEQ 8000 capillary sequencer, and fragments were analyzed using the Fragment Analysis Software (Beckman-Coulter Inc., Fullerton, CA, USA). Genotypes were checked for null alleles, stuttering and allelic drop-out, using MICRO-CHECKER v. 2.2.3 [37]. GENCLONE 2.0 [38] was used to distinguish between unique genotypes and repeated genotypes produced by vegetative reproduction through reattachment of adventitious branches.

\section{Statistical analyses}

\section{Structural equation modelling}

Structural equation models (SEM) were used to distinguish which factors affect the formation of adventitious 


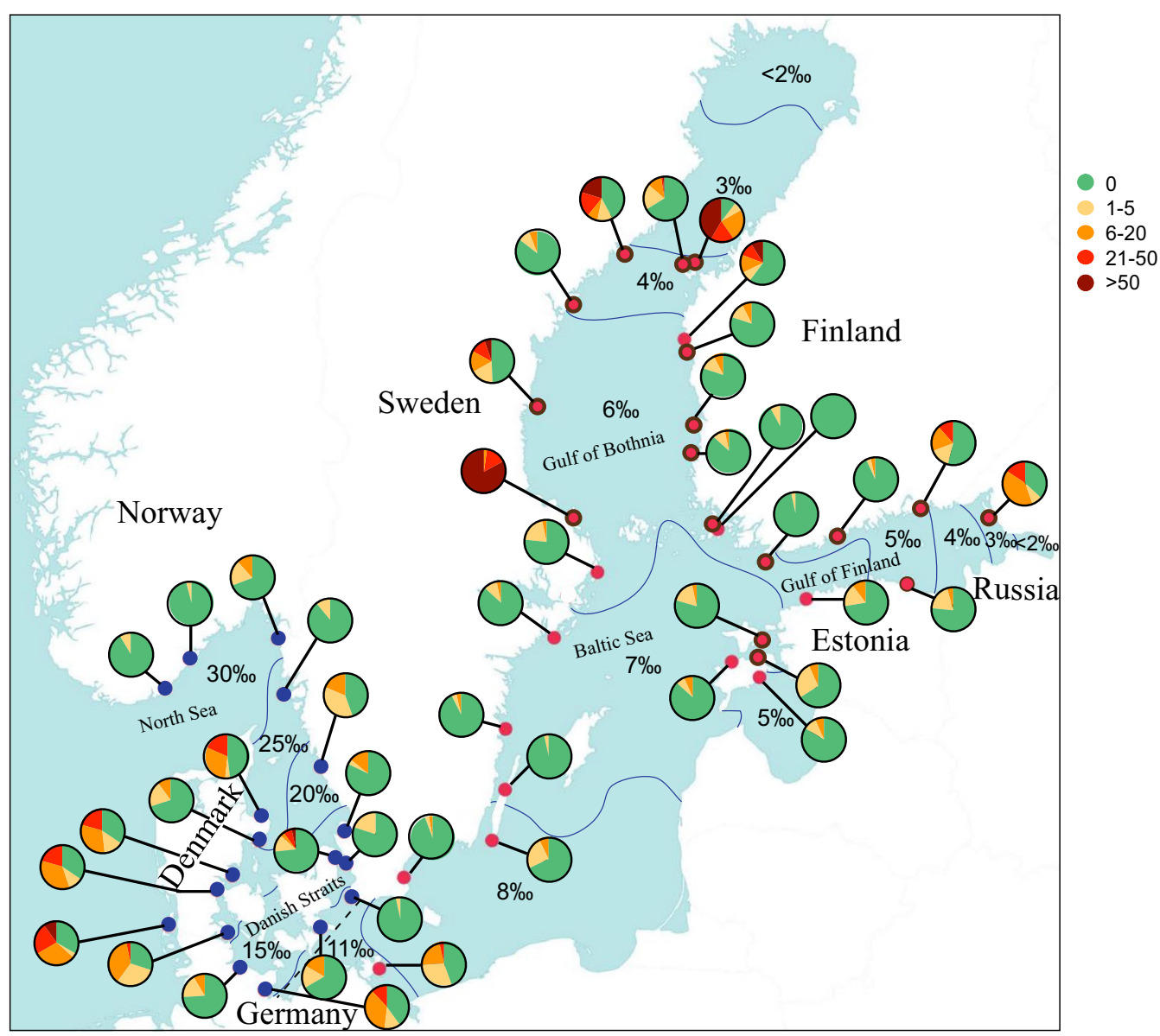

Fig. 2 Map of the study area illustrating the salinity gradient from the eastern North Sea and into the Baltic Sea. Sampling sites from the transition zone and eastern North Sea are represented by blue (dark) circles and sites from the Baltic Sea are represented by red (light). Genotyped individuals within the Baltic Sea sites are represented by a black circle perimeter. The dashed line indicates the border between the Baltic Sea and the Danish Straits used in this study. Pie chart categories indicate the ratio of individuals in each population with a given number of adventitious branches, assembled into categories

branches. Separate structural equation models were used for individuals from the two sampling areas, the Baltic Sea $(\mathrm{n}=1458)$, and eastern North Sea and the transition zone $(n=527)$ (Fig. 2). In addition, we also conducted analyses of a subset of the populations in the Baltic Sea where it was possible to unambiguously identify clones $(n=348)$ from unique genotypes $(n=443)$, i.e. asexually and sexually derived individuals, respectively. Within the clonal subgroup one very dominant genotype (183 individuals of the same clone) was excluded.

Our primary goal was to find out which factors affect formation of adventitious branches in our two study regions, and we therefore studied the number of adventitious branches in relation to several parameters: temperature, salinity, phosphate, nitrate, turbidity, oxygen, thallus area, and grazing pressure. Structural equation modeling makes it possible to separate the effect of each factor into direct, indirect, and total (the sum of direct and indirect) effects. Factors with strong indirect effects exert their influence by having strong effects on other factors in the analysis. We focused on factors that had either a strong direct or a strong total effect on the number of adventitious branches.

Before SEM analysis, all predictor variables were standardised and tested for multi-collinearity by calculating the correlation coefficient for all possible combinations between the factors, and the variance inflation factor (VIF) was calculated for each predictor. All correlation coefficients were below 0.7 and all VIFs less than 2 , indicating that they do not exhibit collinearity [39]. A theoretical model was constructed based on these results and previous knowledge. From this starting point, 
non-significant paths were removed one at a time, starting with the highest p-value pathway. Modification indices were used as a guide to add missing paths, but only where those paths were ecologically reasonable. These steps were repeated until further changes did not affect the significance of the $\chi^{2}$ value. We report the model with the lowest Akaike Information Criterion (AIC) and good fit indices (Table 1).

For each structural equation model we report five fit indices with respective cut-off values for a 'good fit': Chi-square $(>0.05)$, CFI (the comparative fit index; CFI $\geq 0.95$ ) [40]; TLI (Tucker-Lewis index; TLI $\geq 0.95$ ) [41]; RMSEA (the root mean square error of approximation; RMSEA $\leq 0.08$ [42]; and SRMR (standardized rootmean-square residual; SRMR $\leq 0.06$ ) [40].

Structural Equation Models were run in RStudio (version 1.0.136) using the lavaan package [43]. Path diagrams were generated with the package SemPlot [44].

\section{Comparison between clones and genetically unique individuals}

A Welch's $t$-test was used in RStudio (version 1.0.136) to investigate whether clonal individuals $(\mathrm{n}=531)$ had more adventitious branches than genetically unique individuals $(\mathrm{n}=443)$. Welch's $t$-test was chosen since homogeneity of variance could not be assumed [45].

\section{Results}

The prevalence, as well as number, of adventitious branches varied between geographical areas, with the highest prevalence in the south west (Danish coast) and in the north east (northern Swedish and Finnish coasts) (Fig. 2). Additionally, the innermost sites of the Gulf of Finland also had high prevalence of adventitious branches (Fig. 2).

For all structural equation models performed, fit indices indicated that the observed data did not differ statistically from the model, indicating a good model fit (Table 1). Within the Baltic Sea, temperature, salinity, oxygen, and nitrate all had negative total effects on the number of adventitious branches, with temperature, salinity and oxygen generating the strongest total effects (Fig. 3, Table 2). Positive, but weaker, effects were observed for increased thallus area, turbidity, and phosphate (Fig. 3, Table 2). Notably, grazing had a non-significant effect on the number of adventitious branches in Fucus spp. from the Baltic Sea.

Structural equation model analysis of the transition zone and eastern North Sea sites revealed that high levels of salinity, phosphate, turbidity, temperature, and thallus area had significant positive direct effects and positive total effects on the number of adventitious branches per thallus in this area (Fig. 4, Table 3). This was in marked contrast to the results for the Baltic Sea, where, in particular, increased salinity had the opposite effect. Oxygen, nitrogen, and grazing all showed nonsignificant effects in the transition zone and eastern North Sea (Fig. 4, Table 3).

The structural equation models for both clones and genetically unique individuals from the northern Baltic Sea demonstrated a similar pattern to that seen for the whole Baltic Sea. In genetically unique individuals, increasing temperature, oxygen, and salinity had negative direct effects (i.e. fewer adventitious branches), while increased levels of phosphate instead showed a positive direct effect (i.e. more adventitious branches). Thallus area, turbidity, nitrate and grazing all had non-significant effects (Additional file 1: Figure A1, Table A1). In clonal individuals, higher temperature, oxygen, nitrate, and salinity all showed negative direct effects on number of adventitious branches, while increased phosphate and thallus area generated positive direct effects. Turbidity and grazing did not show any significant effects among the clonal thalli (Additional file 1: Figure A2, Table A2).

Average number of adventitious branches was much higher in clonal individuals $($ mean $=26.0$;

Table 1 SEM statistics

\begin{tabular}{llllllll}
\hline Model & df & $\mathbf{X}^{\mathbf{2}}$ & $\mathbf{p}$ & CFI & TLI & RMSEA & SRMR \\
\hline $\begin{array}{l}\text { Baltic Sea } \\
\begin{array}{l}\text { Transition zone and east- } \\
\text { ern North Sea }\end{array}\end{array}$ & 8 & 13.055 & 0.110 & $0.99^{*}$ & $0.99^{*}$ & $0.021^{*}$ & $0.013^{*}$ \\
$\begin{array}{l}\text { Genetically unique } \\
\text { genotypes }\end{array}$ & 5 & 11.18 & 0.131 & $0.99^{*}$ & $0.99^{*}$ & $0.034^{*}$ & $0.020^{*}$ \\
$\begin{array}{l}\text { Clones } \\
\text { lones }\end{array}$ & 4 & 7.443 & 0.190 & $0.99^{*}$ & $0.99^{*}$ & $0.033^{*}$ & $0.010^{*}$ \\
\end{tabular}

Fit indices for the four structural equation models. For each model we report five fit indices: Chi-square, CFI the comparative fit index, TLITucker-Lewis index, RMSEA the root mean square error of approximation, $S R M R$ standardized root-mean-square residual, using the following cut-off values for a 'good fit': CFI $\geq 0.95$, $T L I \geq 0.95$, RMSEA $\leq 0.08$, SRMR $\leq 0.06[31,40-42]$

*Denotes significant values 


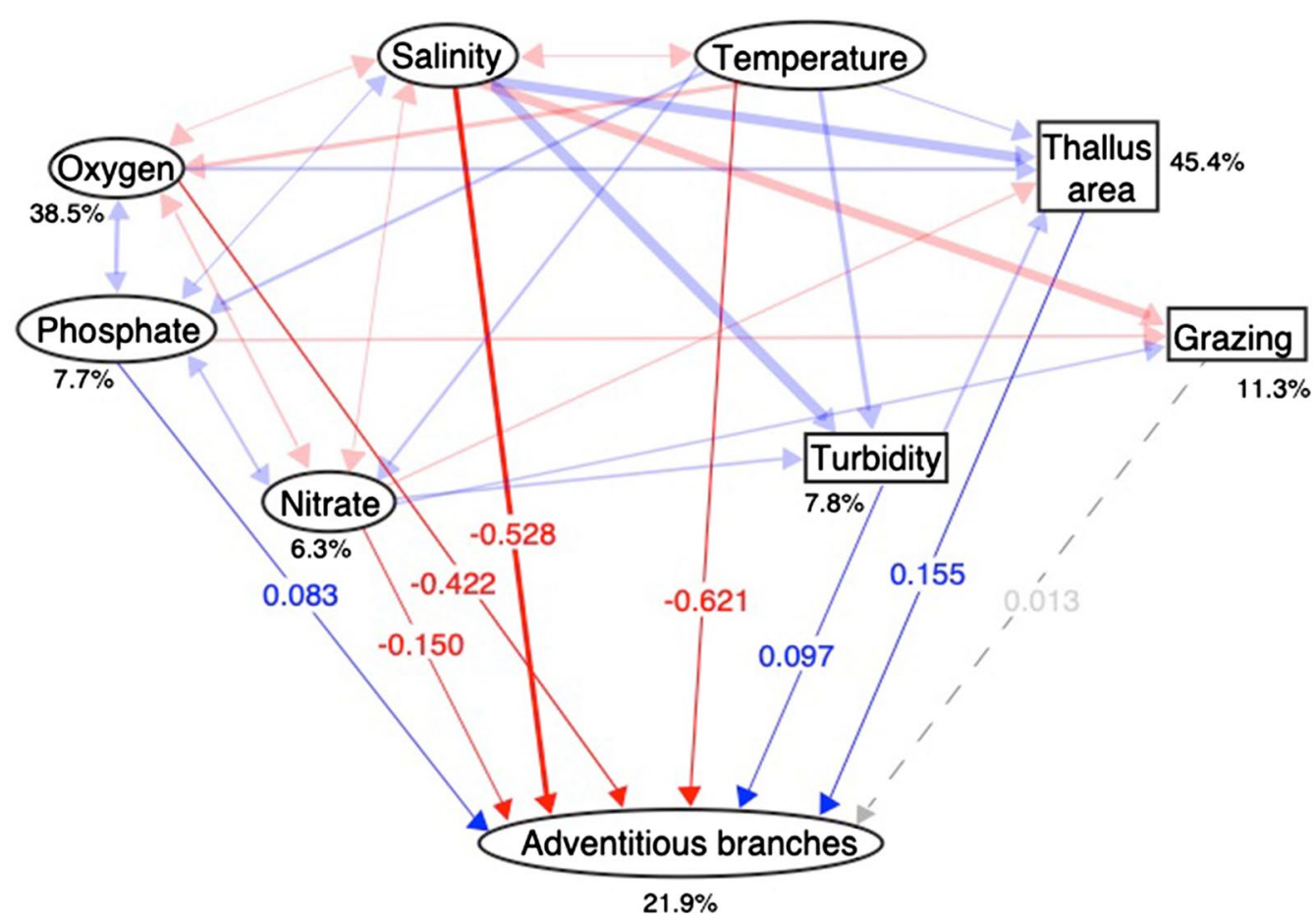

Fig. 3 Path diagram based on structural equation modelling showing how the number of adventitious branches per thallus in Baltic Sea Fucus spp. populations is affected by different environmental factors. Red arrows indicate negative path coefficients, blue arrows indicate positive path coefficients, and dashed gray arrows indicate non-significant paths. All path coefficients are standardized. Variables presented in rectangles are biotic while those presented in ovals are abiotic (with the exception of adventitious branches). Percentages indicate the variance explained by the model, all correlation coefficients are low $(p<0.00001)$

Table 2 Estimated standardized total effects (i.e. the sum of the direct effect and all possible indirect effects) and direct effects with corresponding p-values from the structural equation model for Fucus spp. populations located in the Baltic Sea

\begin{tabular}{lclc}
\hline & Direct effect & p-value (direct) & Total effect \\
\hline Thallus area $\left(\mathrm{cm}^{2}\right)$ & 0.155 & 0.000 & 0.155 \\
Turbidity & 0.097 & 0.003 & 0.177 \\
Grazing & 0.013 & 0.601 & 0.013 \\
Nitrate $(\mu \mathrm{mol} / \mathrm{l})$ & -0.150 & 0.000 & -0.157 \\
Oxygen $(\mathrm{ml} / \mathrm{l})$ & -0.422 & 0.000 & -0.355 \\
Phosphate $(\mu \mathrm{mol} / \mathrm{l})$ & 0.083 & 0.006 & 0.080 \\
Salinity & -0.528 & 0.000 & -0.468 \\
Temperature $\left({ }^{\circ} \mathrm{C}\right)$ & -0.621 & 0.000 & -0.351 \\
\hline
\end{tabular}

Positive denotes an increase in the number of adventitious branches

95\% CI 21.7-28.4) than in genetically unique individuals (mean $=4.0$; 95\% CI 1.6-4.5) (Welch's $t$-test, $\left.t_{719}=11.86 ; \mathrm{p}<0.0001\right)$.

\section{Discussion}

In the Baltic Sea, low salinity, temperature, and oxygen were all associated with high number of adventitious branches, suggesting that increased physical stress promotes formation of adventitious branches. Outside the Baltic Sea the pattern was very different. High levels of salinity together with increased availability of phosphate and high turbidity were associated with increased number of adventitious branches. In general, the effects of environmental factors were weaker in the marine environment than in the brackish Baltic Sea.

The positive effects of phosphate and turbidity on the number of adventitious branches observed in the more marine regions were linked to phytoplankton blooms decreasing light penetration [46] and imposing light-stress on fucoid thalli. Such a stress might induce increased formation of adventitious branches. For example, it has been shown in some macroalgae that light intensity and wavelength can play a role in formation of adventitious tissue. Uji et al. [11] found that Sargassum horneri cultures grown under white and blue light developed more adventitious tissue than those cultured under red light; broadly equivalent responses were seen in Laminariales [47], but not in higher plants [48]. There 


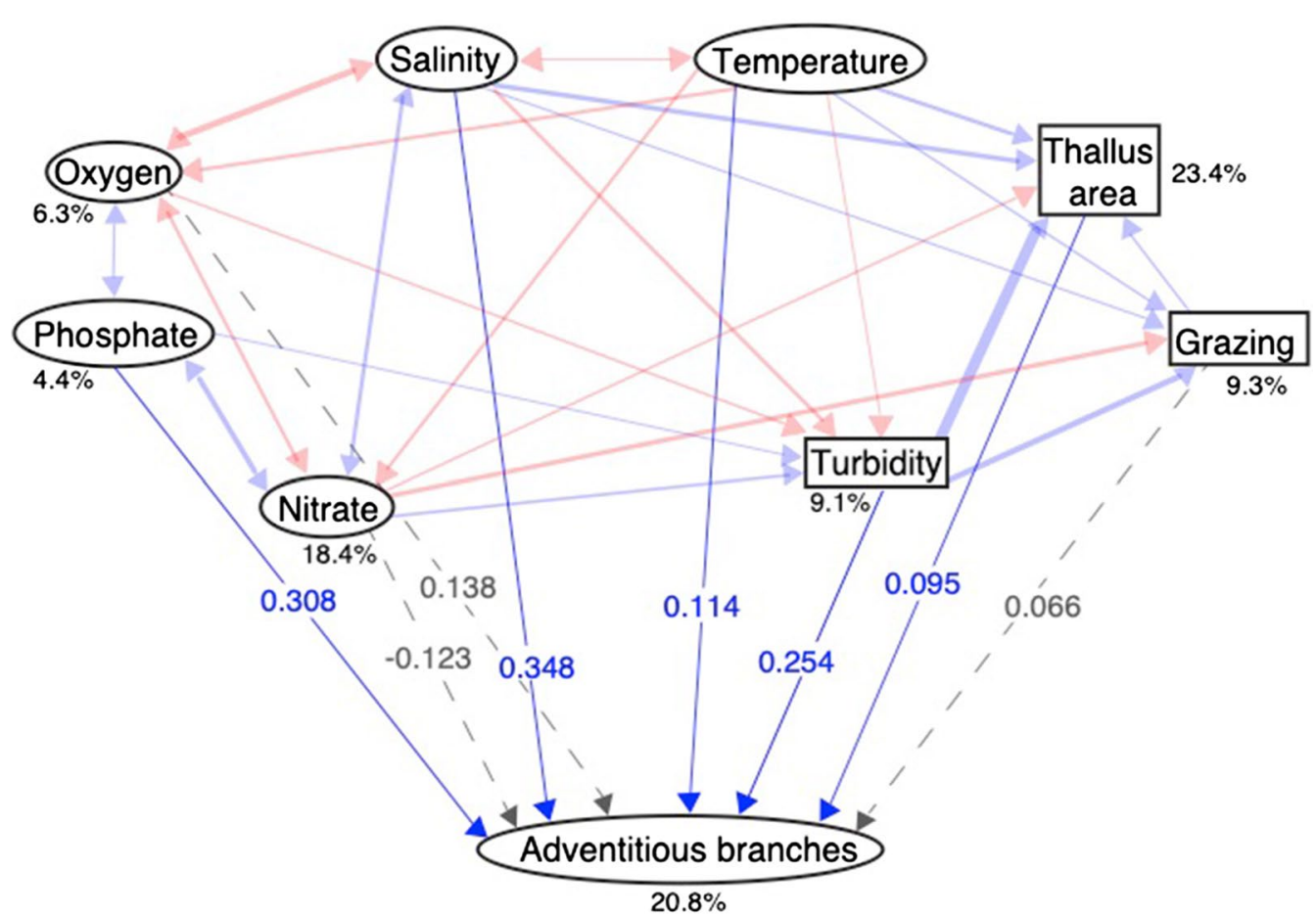

Fig. 4 Path diagram based on structural equation modelling showing how the number of adventitious branches per thallus in Fucus spp. populations from the transition zone and eastern North Sea is affected by different environmental factors. Red arrows indicate negative path coefficients, blue arrows indicate positive path coefficients, and dashed gray arrows indicate non-significant paths. All path coefficients are standardized. Variables presented in rectangles are biotic while those presented in ovals are abiotic (with the exception of adventitious branches). Percentages indicate the variance explained by the model, all correlation coefficients are low ( $p<0.00001$ except nitrate which is low significant $p=0.000114)$

Table 3 Estimated standardized total effects (i.e. the sum of the direct effect and all possible indirect effects) and direct effects with corresponding p-values from the structural equation model for Fucus spp. populations located in the transition zone and the eastern North Sea

\begin{tabular}{lclc}
\hline & Direct effect & p-value (direct) & Total effect \\
\hline Thallus area $\left(\mathrm{cm}^{2}\right)$ & 0.095 & 0.032 & 0.095 \\
Turbidity & 0.254 & 0.000 & 0.313 \\
Grazing & 0.066 & 0.107 & 0.075 \\
Nitrate $(\mu \mathrm{mol} / \mathrm{l})$ & -0.123 & 0.187 & -0.145 \\
Oxygen $(\mathrm{m} / / \mathrm{l})$ & 0.138 & 0.094 & 0.158 \\
Phosphate $(\mu \mathrm{mol} / \mathrm{l})$ & 0.308 & 0.000 & 0.308 \\
Salinity & 0.348 & 0.001 & 0.161 \\
Temperature $\left({ }^{\circ} \mathrm{C}\right)$ & 0.114 & 0.026 & 0.078 \\
\hline
\end{tabular}

Positive denotes an increase in the number of adventitious branches

are too few data to draw definitive conclusions; however, it is interesting to note that Fucus spp. grow exclusively subtidally (and at greater depths) in the Baltic Sea than in the transition zone and eastern North Sea [49].
The hypothesis that grazing induces production of adventitious branches in fucoids was proposed as early as the nineteenth century (Oltmanns 1889 from [50]). This hypothesis has since been supported by observations of a correlation between adventitious branch production and grazer (Littorina spp.) density, as well as by demonstrated grazing preferences associated with polyphenolic compound content of adventitious branches relative to 'normal meristematic tissue' from apices and thalli [10]. In the present study, however, we did not find a relationship between grazing intensity and adventitious branch formation in either of the two regions, despite the fact that grazing can be intense both in the southern parts of the Baltic Sea and in the marine region [28].

In both study regions, most direct effects on the formation of adventitious branches were a small fraction of the total effects (Tables 2,3), indicating the importance of indirect effects of biotic and abiotic drivers. A singular exception to this pattern was present in the Baltic, however, where the direct (negative) effect of salinity on adventitious branches was approximately equal to the overall total effect. Nonetheless, total effect of salinity on adventitious branches in the Baltic Sea were less 
than those of temperature, once again indicating the importance of indirect effects. Outside the Baltic Sea, in the transition zone and eastern North Sea, effects were generally weaker, and patterns more complex, which is reflected in proportionally greater indirect effects ( $c f$ difference between direct effect and total effect in Tables 2, 3 ). Perhaps, formation of adventitious branches is more related to physical stress in the Baltic Sea Fucus spp., a region that was recently invaded by Fucus spp. and where it lives close to its range margin. In contrast, physical stress from the environment affecting production of adventitious branches may be relaxed in a more marine habitat, although North Sea Fucus spp. is more regularly exposed to environmental fluctuations as it inhabits the intertidal zone while it lives subtidally in the Baltic Sea [49].

The variables which exerted the strongest effect on the number of adventitious branches were the same for both clones and unique genotypes in the area where these coexisted (the northern Baltic Sea), but the effect strength (both direct and indirect) was much higher on clonal individuals. In addition, individual thalli of clones had on average more adventitious branches than those of unique genotypes, which we interpret as a consequence of selection favoring adventitious branch formation among asexual lineages to increase vegetative recruitment among asexual lineages. In both the Baltic Sea and the transition zone and eastern North Sea the models explained about $20 \%$ of the observed variation in number of adventitious branches. We here argue that the contribution of genetically-derived phenotypic variation to the remaining $80 \%$ unexplained variation is important. The reason we believe so is that when we tested the effects of environmental drivers on the number of adventitious branches in clonal individuals (effectively increasing the number of environmental replicates per genotype, Additional file 1: Figure A2) we found these explained $62 \%$ of the variation in number of adventitious branches. This strongly supports the suggestion that genetic factors contributed to the unexplained variance in the Baltic Sea and transition zone. This result also corroborates earlier observations of genetic variation among clones in number of adventitious branches [51].

\section{Conclusion}

We show that the number of adventitious branches in natural populations of Fucus spp. are strongly affected by several environmental factors, in particular salinity, and that the effects of these factors differ between sites inside and outside the Baltic Sea: inside, the number of adventitious branches increased with declining salinity, whereas the opposite relationship was seen outside. Experimental work is needed to determine whether the environmental factors induce adventitious branch formation through a plastic response, or if they select for individuals that are genetically disposed to generate more adventitious branches. In addition, we suggest that variation among populations may be due to genetic differences resulting either from local adaptation uncorrelated to the physical factors we measured, or from stochastic effects of population separation. Interestingly, the formation of adventitious branches is a general and ancestral feature of marine populations of fucoid species (e.g. [8, 12, 52]), but in the Baltic Sea it has been a key component in the asexual recruitment and colonization of this brackish water environment. Identifying the environmental factors that drive formation of adventitious branches is an important step towards an increased understanding of how and why asexual reproduction is predominant in large parts of the Baltic Sea.

\section{Additional file}

Additional file 1. Tables and figures containing results from structural equation models for genetically unique and cloned individuals of Fucus spp. from the Baltic Sea, respectively.

\section{Acknowledgements}

We thank Hanna Corell, Luca Rugiu, Veijo Jormalainen, Britta Meyer, Melanie Heckwolf, Merli Pärnoja, Carl André, Marina Panova, and Nikolaj Kovaltchouk who contributed to the fieldwork, and we thank three anonymous reviewers for comments on an earlier version of this manuscript.

\section{Authors' contributions}

KJ conceived the idea and planned the study with HP, AK, and RTP. KJ, RTP, and PDW collected the algae. RTP did the genotyping and AK performed the image analysis of the photos. PRJ provided the environmental data. AK performed the statistical analysis with support from JNH. AK and KJ wrote the manuscript. All authors discussed the results and revisions to the final manuscript. All authors read and approved the final manuscript.

\section{Funding}

This work resulted from the BONUS BAMBI project which was supported by BONUS (Art 185), funded jointly by the EU and the Swedish research council FORMAS; additional funding was provided by the Swedish Research Council VR, through a Linnaeus grant to the Centre for Marine Evolutionary Biology (CeMEB), and Rådman och Fru Ernst Collianders Stiftelse. Apart from funding the study, the funding bodies have not had any influence on the design, collection, analysis, interpretation of the data or the writing of the manuscript.

\section{Availability of data and materials}

The dataset analysed in the current study is available from the corresponding author on reasonable request.

Ethics approval and consent to participate

Not applicable.

Consent for publication

Not applicable.

Competing interests

The authors declare that they have no competing interests. 
Received: 29 August 2018 Accepted: 28 May 2019

Published online: 04 June 2019

\section{References}

1. Wilcox H. Regeneration of injured root systems in noble fir. Bot Gaz. 1955;116:221-34

2. Waaland SD, Cleland RE. Cell repair through cell fusion in the red alga Griffithsia pacifica. Protoplasma. 1974;79:185-96.

3. Haissig B, Davis T, Riemenschneider D. Researching the controls of adventitious rooting. Physiol Plant. 1992;84:310-7.

4. Bryant J. Phytochemical deterrence of snowshoe hare browsing by adventitious shoots of four Alaskan trees. Science. 1981;213:889-90.

5. Maini JS, Horton KW. Vegetative propagation of Populus spp.: I. Influence of temperature on formation and initial growth of aspen suckers. Can J Bot. 1966:44:1183-9.

6. Mundhara R, Rashid A. Regeneration of shoot-buds on hypocotyl of Linum seedlings: a stress-related response. Plant Sci. 2001;16:19-25.

7. Ikeda-Iwai M, Umehara M, Satoh S, Kamada H. Stress-induced somatic embryogenesis in vegetative tissues of Arabidopsis thaliana. Plant J. 2003;34:107-14.

8. Fritsch FE. The structure and reproduction of the algae, vol. II. London: Cambridge University Press; 1977.

9. Fagerberg WR, Dawes CJ. Studies on Sargassum. I. A light microscopic examination of the wound regeneration process in mature stipes of $S$. filipendula. Am J Bot. 1976;63:110-9.

10. Van Alstyne KL. Adventitious branching as a herbivore-induced defense in the intertidal brown alga Fucus distichus. Mar Ecol Prog Ser. 1989;56:169-76.

11. Uji T, Nanaumi D, Kawagoe C, Saga N, Miyashita K. Factors influencing the induction of adventitious bud and callus in the brown alga Sargassum horneri (Turner) C. Agardh. J Appl Phycol. 2016;28:2435-43.

12. Fulcher RG, McCully ME. Histological studies on the genus Fucus. IV. Regeneration and adventive embryony. Can J Bot. 1969;47:1643-9.

13. Fulcher RG, McCully ME. Histological studies on the genus Fucus. V. An autoradiographic and electron microscopic study of the early stages of regeneration. Can J Bot. 1971;49:161-5.

14. McCook LJ, Chapman ARO. Community succession following massive ice-scour on a rocky intertidal shore: recruitment, competition and predation during early, primary succession. Mar Biol. 1993;115:565-75.

15. Tatarenkov A, Bergström L, Jönsson RB, Serrão EA, Kautsky L, Johannesson K. Intriguing asexual life in marginal populations of the brown seaweed Fucus vesiculosus. Mol Ecol. 2005;14:647-51.

16. Johannesson $\mathrm{K}$, Johansson D, Larsson KH, Huenchuñir CJ, Perus J, Forslund $\mathrm{H}$, et al. Frequent clonality in fucoids (Fucus radicans and Fucus vesiculosus; fucales, Phaeophyceae) in the Baltic Sea. J Phycol. 2011:47:990-8

17. Ardehed A, Johansson D, Sundqvist L, Schagerström E, Zagrodzka Z, Kovaltchouk NA, Bergström L, Kautsky L, Rafajlovic M, Pereyra RT, Johannesson K. Divergence within and among seaweed siblings (Fucus vesiculosus and F. radicans) in the Baltic Sea. PLOS ONE. 2016;11(8):e0161266.

18. Rothäusler E, Rugiu L, Jormalainen V. Forecast climate change conditions sustain growth and physiology but hamper reproduction in rangemargin populations of a foundation rockweed species. Mar Environ Res. 2018;141:205-13.

19. Serrão EA, Kautsky L, Brawley SH. Distributional success of the marine seaweed Fucus vesiculosus L. in the brackish Baltic Sea correlates with osmotic capabilities of Baltic gametes. Oecologia. 1996;107:1-12.

20. Serrão EA, Brawley SH, Hedman J, Kautsky L, Samuelsson G. Reproductive success of Fucus vesiculosus (Phaeophyceae) in the Baltic Sea. J Phycol. 1999:35:254-69.

21. Snoeijs-Leijonmalm P, Andrén E. Whis is the Baltic Sea so special to live in? In: Snoeijs-Leijonmalm P, Schubert H, Radziejewska T, editors. Biological oceanography of the Baltic Sea. Dordrecht: Springer Science \& Business Media; 2017. p. 23-84

22. Johannesson K, Andre C. Life on the margin: genetic isolation and diversity loss in a peripheral marine ecosystem, the Baltic Sea. Mol Ecol. 2006;15:2013-29.
23. Lamichhaney S, Barrio AM, Rafati N, Sundström G, Rubin CJ, Gilbert $E R$, et al. Population-scale sequencing reveals genetic differentiation due to local adaptation in Atlantic herring. Proc Natl Acad Sci USA. 2012;109:19345-50. https://doi.org/10.1073/pnas.1216128109.

24. Luttikhuizen PC, Drent J, Peijnenburg KT, Van der Veer HW, Johannesson K. Genetic architecture in a marine hybrid zone: comparing outlier detection and genomic clines analysis in the bivalve Macoma balthica. Mol Ecol. 2012;21:3048-61.

25. Leidenberger S, Harding K, Jonsson PR. Ecology and distribution of the isopod genus /dotea in the Baltic Sea: key species in a changing environment. J Crust Biol. 2012;32:359-89.

26. Andersen JH, Carstensen J, Conley DJ, Dromph K, Fleming-Lehtinen V, Gustafsson BG, Josefson AB, Norkko A, Villnäs A, Murray C. Long-term temporal and spatial trends in eutrophication status of the Baltic Sea. Biol Rev. 2017;92:135-49.

27. Wikström SA, Steinarsdottir MB, Kautsky L, Pavia H. Increased chemical resistance explains low herbivore colonization of introduced seaweed. Oecologia. 2006;148:593-601.

28. Nylund GM, Pereyra RT, Wood HL, Johannesson K, Pavia H. Increased resistance towards generalist herbivory in the new range of a habitatforming seaweed. Ecosphere. 2012;3:125.

29. Pereyra RT, Bergström L, Kautsky L, Johannesson K. Rapid speciation in a newly opened postglacial marine environment, the Baltic Sea. BMC Evol Biol. 2009:9:70.

30. Pereyra RT, Huenchuñir C, Johansson D, Forslund H, Kautsky L, Jonsson $P R$, Johannesson K. Parallel speciation or long-distance dispersal? Lessons from seaweeds (Fucus) in the Baltic Sea. J Evol Biol. 2013;26:1727-37.

31. Schneider CA, Rasband WS, Eliceiri KW. NIH Image to ImageJ: 25 years of image analysis. Nat Methods. 2012;9:671-5.

32. Bellini C, Pacurar DI, Perrone I. Adventitious roots and lateral roots: similarities and differences. Annu Rev Plant Biol. 2014;65:639-66.

33. Steffens B, Wang J, Sauter M. Interactions between ethylene, gibberellin and abscisic acid regulate emergence and growth rate of adventitious roots in deepwater rice. Planta. 2006;223:604-12

34. Ayi Q, Zeng B, Liu J, Li S, van Bodegom PM, Cornelissen JH. Oxygen absorption by adventitious roots promotes the survival of completely submerged terrestrial plants. Ann Bot. 2016;118:675-83.

35. Panova M, Aronsson H, Cameron RA, Dahl P, Godhe A, Lind U, OrtegaMartinez O, Pereyra R, Tesson SV, Wrange AL, Blomberg A. DNA extraction protocols for whole-genome sequencing in marine organisms. In: Bourlat S, editor. Marine genomics. New York: Humana Press; 2016. p. 13-44.

36. Engel CR, Brawley SH, Edwards KJ, Serrão E. Isolation and cross-species amplification of microsatellite loci from the fucoid seaweeds Fucus vesiculosus, F. serratus and Ascophyllum nodosum (Heterokontophyta, Fucaceae). Mol Ecol Notes. 2003;3:180-2.

37. Van Oosterhout C, Hutchinson WF, Wills DP, Shipley P. MICRO-CHECKER: software for identifying and correcting genotyping errors in microsatellite data. Mol Ecol Notes. 2004;4:535-8.

38. Arnaud-Haond S, Duarte CM, Alberto F, Serrão EA. Standardizing methods to address clonality in population studies. Mol Ecol. 2007;16:5115-39.

39. Kock N, Lynn G. Lateral collinearity and misleading results in variancebased SEM: an illustration and recommendations. J Assoc Inf Syst. 2012:13:546-80.

40. Hu LT, Bentler PM. Cutoff criteria for fit indexes in covariance structure analysis: conventional criteria versus new alternatives. Struct Equ Modeling. 1999;6:1-55.

41. Tucker $L R$, Lewis $C$. A reliability coefficient for maximum likelihood factor analysis. Psychometrika. 1973;38:1-10.

42. Browne MW, Cudeck R. Alternative ways of assessing model fit. Sociol Methods Res. 1992;21:230-58.

43. Rosseel Y. The lavaan tutorial. 2017. http://lavaan.ugent.be/tutorial/tutor ial.pdf. Accessed 3 May 2017.

44. Epskamp S. semPlot: path diagrams and visual analysis of various SEM packages' output. R package version, 1. 2017. https://rdrr.io/cran/semPI ot/. Accessed 3 May 2017

45. Delacre M, Lakens D, Leys C. Why psychologists should by default use Welch's t-test instead of Student's t-test. Int Rev Soc Psychol. 2017;30:92-101. 
46. Rohde S, Hiebenthal C, Wahl M, Karez R, Bischof K. Decreased depth distribution of Fucus vesiculosus (Phaeophyceae) in the Western Baltic: effects of light deficiency and epibionts on growth and photosynthesis. Eur J Phycol. 2008;43:143-50.

47. Asensi A, Gall EA, Marie D, Billot C, Dion P, Kloareg B. Clonal propagation of Laminaria digitata (Phaeophyceae) sporophytes through a diploid cellfilament suspension. J Phycol. 2001;37:411-7.

48. Hunter DC, Burritt DJ. Light quality influences adventitious shoot production from cotyledon explants of lettuce (Lactuca sativa L.). In Vitro Cell Dev Biol Plant. 2004;40:215-20.

49. Pearson G, Kautsky L, Serrão E. Recent evolution in Baltic Fucus vesiculosus: reduced tolerance to emersion stresses compared to intertidal (North Sea) populations. Mar Ecol Prog Ser. 2000;202:67-79.
50. McLachlan J, Chen LM. Formation of adventive embryos from rhizoidal filaments in sporelings of four species of Fucus (Phaeophyceae). Can J Bot. 1972;50:1841-4.

51. Johansson D, Pereyra RT, Rafajlović M, Johannesson K. Reciprocal transplants support a plasticity-first scenario during colonisation of a large hyposaline basin by a marine macro alga. BMC Ecol. 2017;17:14.

52. Lee RE. Phycology. 5th ed. Cambridge: Cambridge University Press; 2018.

\section{Publisher's Note}

Springer Nature remains neutral with regard to jurisdictional claims in published maps and institutional affiliations.
Ready to submit your research? Choose BMC and benefit from:

- fast, convenient online submission

- thorough peer review by experienced researchers in your field

- rapid publication on acceptance

- support for research data, including large and complex data types

- gold Open Access which fosters wider collaboration and increased citations

- maximum visibility for your research: over 100M website views per year

At BMC, research is always in progress.

Learn more biomedcentral.com/submissions 